Arturo Carpio, MD*

Alfredo Campoverde, MS

Matthew L. Romo,

PharmD, MPH*

Lorena García, MD

Luis M. Piedra, MD

Mónica Pacurucu, MD

Nelson López, MD

Jenner Aguilar, MD

Sebastian López, MD

Luis C. Vintimilla, MD

Ana M. Toral, MD

Pablo Peña-Tapia, MD

Correspondence to

Dr. Carpio:

arturo.carpio@ucuenca.edu.ec

\title{
Validity of a PCR assay in CSF for the diagnosis of neurocysticercosis
}

\section{OPEN}

\section{ABSTRACT}

Objective: To prospectively evaluate the validity of a PCR assay in CSF for the diagnosis of neurocysticercosis (NC).

Methods: We conducted a multicenter, prospective case-control study, recruiting participants from 5 hospitals in Cuenca, Ecuador, from January 2015 to February 2016. Cases fulfilled validated diagnostic criteria for NC. For each case, a neurosurgical patient who did not fulfill the diagnostic criteria for NC was selected as a control. CT and MRI, as well as a CSF sample, were collected from both cases and controls. The diagnostic criteria to identify cases were used as a reference standard.

Results: Overall, 36 case and 36 control participants were enrolled. PCR had a sensitivity of $72.2 \%$ (95\% confidence interval [Cl] 54.8\%-85.8\%) and a specificity of $100.0 \%(95 \% \mathrm{Cl}$ 90.3\%-100.0\%). For parenchymal NC, PCR had a sensitivity of $42.9 \%(95 \% \mathrm{Cl} 17.7 \%-$ $71.1 \%)$, and for extraparenchymal NC, PCR had a sensitivity of $90.9 \%$ (95\% Cl 70.8\%-98.9\%).

Conclusions: This study demonstrated the usefulness of this PCR assay in CSF for the diagnosis of NC. PCR may be particularly helpful for diagnosing extraparenchymal NC when neuroimaging techniques have failed.

Classification of evidence: This study provides Class III evidence that CSF PCR can accurately identify patients with extraparenchymal NC. Neurol Neuroimmunol Neuroinflamm 2017;4:e324; doi: $10.1212 / \mathrm{NXI} .0000000000000324$

\section{GLOSSARY}

$\mathbf{C I}=$ confidence interval; $\mathbf{E P - N C}=$ extraparenchymal neurocysticercosis; $\mathbf{N C}=$ neurocysticercosis; $\mathbf{P}-\mathbf{N C}=$ parenchymal neurocysticercosis.

Accurate diagnosis of neurocysticercosis (NC) is a challenge, perhaps due to poor specificity of clinical and neuroimaging findings and suboptimal predictive values of immunodiagnostic tests. ${ }^{1}$ Parenchymal NC (P-NC) is relatively less problematic to diagnose in comparison with extraparenchymal NC (EP-NC) (i.e., subarachnoid or intraventricular location of cysts). This may be partially due to the greater difficulty to accurately visualize a scolex in EP-NC on imaging, notwithstanding newer MRI techniques. ${ }^{2,3}$

The utility of different PCR assays in CSF for the diagnosis of NC has been reported in case reports and in a small number of diagnostic studies. ${ }^{4-8}$ Development of accurate diagnostic tests for NC is a current research priority. The ideal point-of-care testing would allow detection of a viable cysticercus and identify patients with severe or progressive forms of NC, such as EP-NC. The objective of this study was to prospectively determine the validity of a PCR assay in CSF.

\footnotetext{
*These authors contributed equally to this work.

From Facultad de Ciencias Médicas (A. Carpio, A. Campoverde, L.G., L.M.P.), Universidad de Cuenca, Ecuador; GH Sergievsky Center (A. Carpio), College of Physicians and Surgeons, Columbia University; Department of Epidemiology and Biostatistics (M.L.R.), CUNY Graduate School of Public Health and Health Policy, City University of New York, NY; Hospital del Instituto Ecuatoriano de Seguridad Social (L.M.P., N.L.), José Carrasco Arteaga; Hospital Vicente Corral Moscoso (M.P., J.A.), Ministerio de Salud Pública; Hospital Santa Inés (S.L.); Clínica Santa Ana (L.C.V.); and Hospital Universitario del Río (A.M.T., P.P.-T.), Cuenca, Ecuador.

Funding information and disclosures are provided at the end of the article. Go to Neurology.org/nn for full disclosure forms. The Article Processing Charge was paid by the University of Cuenca, Ecuador.

This is an open access article distributed under the terms of the Creative Commons Attribution-NonCommercial-NoDerivatives License 4.0 (CC BY-NC-ND), which permits downloading and sharing the work provided it is properly cited. The work cannot be changed in any way or used commercially without permission from the journal.
} 
METHODS We evaluated a PCR assay in a multicenter, prospective case-control study, adhering to the Standards for Reporting of Diagnostic Accuracy criteria (stard-statement.org). The ethics committee at the University of Cuenca approved this study and signed informed consent was obtained from all participants. Consecutive pediatric and adult participants were recruited from January 2015 to February 2016 by neurologists (A. Carpio, L.M.P., M.P., A.M.T.) and neurosurgeons (N.L., J.A., P.P.-T., S.L., L.C.V.) at 5 general hospitals in Cuenca, Ecuador. All participants underwent CT and MRI. Cases had to fulfill validated diagnostic criteria for NC. ${ }^{9}$ For each case, a neurosurgical patient who did not fulfill the diagnostic criteria for $\mathrm{NC}$ was selected as a control. A serum sample and CSF sample were collected from both cases and controls. Validated diagnostic criteria to identify cases were used as a reference standard. ${ }^{9}$ Cyst stage and location were based on interpretation of imaging. Cyst stage included the 4 development stages of cysticerci: the vesicular or viable stage, the colloidal and granular-nodular stages in the degenerative or transitional phases, and the calcified stage when the parasite is dead. Cyst location was classified as parenchymal when cysts were located inside the brain tissue and extraparenchymal when cysts were located in the subarachnoid space or inside the ventricular system. Clinicians also recorded data on symptoms, medical history, and results from blood and CSF analysis.

PCR in CSF samples for cases and controls was done using a technique previously described by Michelet et al., ${ }^{7}$ with the exception of using DNA from human cysticerci in addition to DNA from pig cysticerci as controls (figure; amplicons from PCR after separation). Primers designed to amplify the highly repetitive element $\mathrm{pT}$ Tsol9 of the genome were used (GenBank accession no. U45987). The primers used in the PCR to amplify pTsol9 were 5'-CAGGGTGTGACGTCATGG-3' (forward primer; positions 21 to 38,179 to 196 , or 336 to 353) and 5'-GCTAGGCAACTGGCCTCCT-3' (reverse primer; positions 122 to 140 , 280 to 298 , or 437 to 455 ). Laboratory staff was blinded to the diagnosis of all participants.

We first describe our results overall and then compare variables by cases vs controls, and then compare cases with P-NC only vs EP-NC. Categorical variables were compared using Pearson $\chi^{2}$ test (or Fisher exact test, when appropriate) and age in years was compared using the Mann-Whitney $U$ test. Sensitivity and specificity were calculated, along with exact $95 \%$ confidence intervals. All analyses were done in SAS 9.4 (SAS Institute Inc. , Cary, NC) and the significance level was set at a 2 -sided $\alpha$ of 0.05 .

\section{Figure Amplicons from PCR after separation}

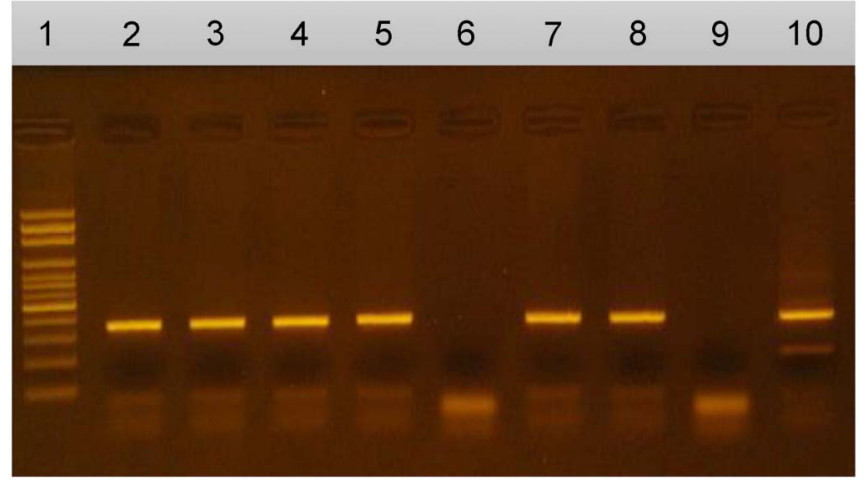

1: Molecular weight marker; 2-5, 7, 8: Positive results; 6: Negative result; 9: Negative control; 10: Positive control.
RESULTS Overall, 44 patients with confirmed NC were screened and 36 were included in the study (exclusions: $\mathrm{n}=5$ refused lumbar puncture; $\mathrm{n}=1$ lost to follow-up; $\mathrm{n}=1$ undue risk of lumbar puncture; $\mathrm{n}=1$ PCR not done). For controls, 40 neurosurgical patients were screened based on having a CSF sample available and 36 were included in the study (exclusions: $\mathrm{n}=3$ later clinical suspicion of $\mathrm{NC}$; $\mathrm{n}=1$ PCR not done). NC was suspected for 3 controls because all had hydrocephalus and positive ELISA for the secreted antigen HP10 in CSF and positive ELISA for Taenia solium antibodies in the serum (data for these assays not shown for all participants).

The median age of participants was 51.5 years and slightly more were male (table 1). There were no significant differences between cases and controls for age, sex, or hospital (data not shown for hospital, $p=0.13)$. Among cases, 9/36 (25.0\%) had previous unsuccessful cysticidal treatment. According to our gold standard diagnosis, $19.4 \%$ of participants had definite P-NC, 19.4\% had probable P-NC, 5.6\% had definite EP-NC, and 55.6\% had definite P-NC plus EP-NC. Among participants with EP-NC, $40.9 \%$ had subarachnoid cysts, $36.4 \%$ had intraventricular cysts, and $22.7 \%$ had both subarachnoid and intraventricular cysts. Participants with NC most often had vesicular cysts $(77.8 \%)$, and among those with vesicular cysts, $71.4 \%$ had multiple vesicular cysts. When comparing cases and controls, significantly more cases had low CSF glucose $(42.9 \%$ vs $11.8 \% ; p=0.006$ ).

PCR was positive in $72.2 \%$ of cases and $0.0 \%$ of controls (table 2). Among cases, PCR was positive in $42.9 \%$ of participants with exclusively P-NC and $90.9 \%$ of participants with EP-NC ( $p=0.006)$. Overall, PCR had a sensitivity of $72.2 \%$ and a specificity of $100.0 \%$. PCR had a sensitivity of $42.9 \%$ for P-NC and a sensitivity of $90.9 \%$ for EP-NC. Sensitivity was $80.0 \%$ (95\% confidence interval [CI] $56.3 \%-94.3 \%$ ) for multiple vesicular cysts, $62.5 \%$ (95\% CI 24.5\%-91.6\%) for single vesicular cysts, $37.5 \%$ (95\% CI 8.5\%-75.5\%) for multiple colloidal cysts, and $80.0 \%$ (95\% CI 44.4\%-97.5\%) for single colloidal cysts.

DISCUSSION The PCR assay had high sensitivity for EP-NC and thus it can quickly confirm cases of EP$\mathrm{NC}$ that are suspected based on symptoms, imaging, and other immunologic tests. EP-NC is the most severe form of the disease and has high fatality, in addition to poor prognosis with severe sequelae. ${ }^{3}$ Based on these results, it seems justifiable to perform a lumbar puncture to perform PCR of the CSF in order to confirm diagnosis of EP-NC and initiate appropriate treatment. 


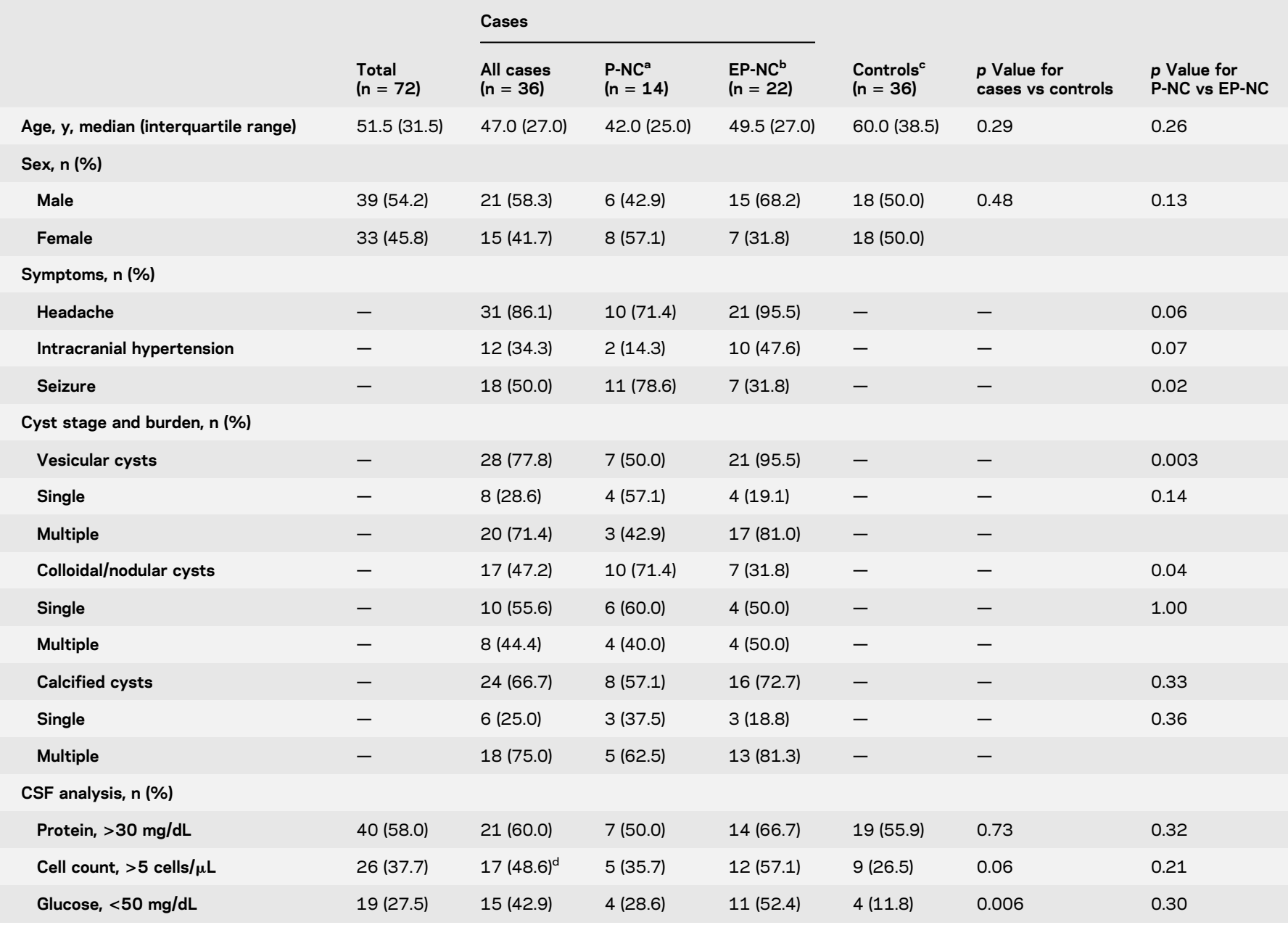

Abbreviations: EP-NC = extraparenchymal neurocysticercosis; P-NC = parenchymal neurocysticercosis.

a Includes probable and definitive P-NC per the gold standard criteria.

${ }^{b}$ Includes participants with definitive EP-NC and definitive P-NC/EP-NC per the gold standard criteria. Most participants (90.9\%) had both parenchymal and extraparenchymal cysts. Of these participants, $40.9 \%$ had only subarachnoid cysts, $36.4 \%$ had only intraventricular cysts, and $22.7 \%$ had both subarachnoid and intraventricular cysts.

${ }^{\mathrm{c} C}$ Control diagnoses were neoplasia (33.3\%), hydrocephalus (25.0\%), cerebrovascular disease (16.7\%), other (13.9\% [included Guillain-Barré syndrome, hygroma, optic neuritis, and severe cerebral trauma]), neurodegenerative disease (5.6\%), and encephalitis (5.6\%). Nine (25\%) control participants had normal pressure hydrocephalus resulting from subarachnoid hemorrhage, head trauma, or bacterial infection of the CNS.

${ }^{d}$ For these $17 \mathrm{NC}$ cases with a cell count $>5,5$ participants had $100 \%$ lymphocytes and among the other 12 participants, polymorphonuclear leukocytes ranged from $6 \%$ to $65 \%$.

In a previous diagnostic study from Mexico, PCR was positive in all cases of P-NC. ${ }^{7}$ This was an unexpected finding as parenchymal cysticerci have restricted contact with the CSF. However, only 7 participants with only P-NC were included in this study, limiting interpretation. In contrast, sensitivity among participants with P-NC in our study was only $42.9 \%$, although CIs were relatively wide due to the small number of participants in this group. Clearly, a study with greater statistical power is needed; however, our findings demonstrate some uncertainty about the usefulness of PCR in ruling in a diagnosis of NC among patients with cysts restricted to the brain parenchyma.

A small study using a real-time PCR assay among immigrant patients in France reported that $T$ solium
DNA could persist in CSF for many years, even after antiparasitic treatment. ${ }^{10}$ In our study, 9 participants with positive PCR were previously treated with cysticidal drugs, suggesting that the larvae may not be totally eliminated by treatment. Further studies are needed to determine if persistence of DNA in the CSF can be used to evaluate the effectiveness of treatment. Finally, our overall conclusions on the usefulness of PCR were similar to those of the study in Mexico using the same PCR assay. ${ }^{7}$ This is important considering the genetic diversity of $T$ solium, but validation in Africa and Asia is needed.

This prospective study demonstrated the usefulness of this PCR assay in CSF for diagnosing NC. PCR had high sensitivity and specificity for EP-NC, which is of particular value since it could be used 


\begin{tabular}{|c|c|c|c|c|c|c|}
\hline \multirow[t]{3}{*}{ PCR results } & validity of the assa & & & \multirow[b]{3}{*}{$\begin{array}{l}\text { Controls } \\
(n=36)\end{array}$} & \multirow[b]{3}{*}{$\begin{array}{l}\text { p Value for } \\
\text { cases vs controls }\end{array}$} & \multirow[b]{3}{*}{$\begin{array}{l}p \text { Value for } \\
\text { P-NC vs EP-NC }\end{array}$} \\
\hline & \multicolumn{3}{|l|}{ Cases $(n=36)$} & & & \\
\hline & $\begin{array}{l}\text { All cases } \\
(n=36)\end{array}$ & $\begin{array}{l}\text { P-NC } \\
(n=14)\end{array}$ & $\begin{array}{l}\text { EP-NC } \\
(n=22)\end{array}$ & & & \\
\hline \multicolumn{7}{|l|}{ PCR results, $\mathrm{n}(\%)$} \\
\hline Positive & 26 (72.2) & $6(42.9)$ & 20 (90.9) & $0(0.0)$ & $<0.0001$ & 0.006 \\
\hline Negative & $10(27.8)$ & $8(57.1)$ & $2(9.1)$ & $36(100.0)$ & & \\
\hline \multicolumn{7}{|l|}{ Validity } \\
\hline Sensitivity, \% (95\% Cl) & $72.2(54.8-85.8)$ & $42.9(17.7-71.1)$ & $90.9(70.8-98.9)$ & - & - & - \\
\hline Specificity, \% (95\% Cl) & $100.0(90.3-100.0)$ & $100.0(90.3-100.0)$ & $100.0(90.3-100.0)$ & - & - & - \\
\hline
\end{tabular}

Abbreviations: $\mathrm{Cl}$ = confidence interval; EP-NC = extraparenchymal neurocysticercosis; P-NC = parenchymal neurocysticercosis.

when neuroimaging techniques have failed. Given the small size of this study, future studies with sufficient statistical power are needed to better understand the value of this assay in specific patient subgroups based on cyst phase, location, and burden.

\section{AUTHOR CONTRIBUTIONS}

Arturo Carpio: study concept and design, acquisition of data, analysis and interpretation of data, manuscript drafting, study coordination, obtaining funding. Alfredo Campoverde: acquisition of data, critical revision and approval of the manuscript. Matthew L. Romo: study concept and design, analysis and interpretation of data, statistical analysis, manuscript drafting. Lorena García: acquisition of data, study supervision, critical revision and approval of the manuscript. Luis M. Piedra: acquisition of data, critical revision and approval of the manuscript. Mónica Pacurucu: acquisition of data, critical revision and approval of the manuscript. Nelson López: acquisition of data, critical revision and approval of the manuscript. Jenner Aguilar: acquisition of data, critical revision and approval of the manuscript. Sebastian López: acquisition of data, critical revision and approval of the manuscript. Luis C. Vintimilla: acquisition of data, critical revision and approval of the manuscript. Ana M. Toral: acquisition of data, critical revision and approval of the manuscript. Pablo Peña-Tapia: acquisition of data, critical revision and approval of the manuscript.

\section{ACKNOWLEDGMENT}

The authors thank the study participants from Hospital Vicente Corral Moscoso, Hospital del Instituto Ecuatoriano de Seguridad Social, Hospital Universitario del Río, Hospital Santa Inés, and Clínica Santa Ana in Cuenca, Ecuador; and Agnès Fleury, MD, PhD, for commentary on an earlier draft of the manuscript.

\section{STUDY FUNDING}

This study was funded by the Dirección de Investigación (DIUC), Universidad de Cuenca, Ecuador. The funders had no role in study design, data collection and interpretation, or the decision to submit the work for publication.

\section{DISCLOSURE}

The authors report no disclosures. Go to Neurology.org/nn for full disclosure forms.
Received September 8, 2016. Accepted in final form December 7, 2016.

\section{REFERENCES}

1. Carpio A, Romo ML, Parkhouse RM, Short B, Dua T. Parasitic diseases of the central nervous system: lessons for clinicians and policy makers. Expert Rev Neurother 2016; 4:1-14.

2. Lerner A, Shiroishi MS, Zee CS, Law M, Go JL. Imaging of neurocysticercosis. Neuroimaging Clin N Am 2012;22: 659-676.

3. Carrillo Mezo R, Lara García J, Arroyo M, Fleury A. Relevance of $3 \mathrm{D}$ magnetic resonance imaging sequences in diagnosing basal subarachnoid neurocysticercosis. Acta Trop 2015;152:60-65.

4. Meri T, Jokiranta TS, Granat S, Collander F, Valtonen M, Meri S. Diagnosis of atypical neurocysticercosis by polymerase chain reaction analysis: case report. Clin Infect Dis 1999;28:1331-1332.

5. Almeida CR, Ojopi EP, Nunes CM, et al. Taenia solium DNA is present in the cerebrospinal fluid of neurocysticercosis patients and can be used for diagnosis. Eur Arch Psychiatry Clin Neurosci 2006;256:307-310.

6. Hernandez M, Gonzalez LM, Fleury A, et al. Neurocysticercosis: detection of Taenia solium DNA in human cerebrospinal fluid using a semi-nested PCR based on HDP2. Ann Trop Med Parasitol 2008;102:317-323.

7. Michelet L, Fleury A, Sciutto E, et al. Human neurocysticercosis: comparison of different diagnostic tests using cerebrospinal fluid. J Clin Microbiol 2011;49:195-200.

8. Rottbeck R, Nshimiyimana JF, Tugirimana P, et al. High prevalence of cysticercosis in people with epilepsy in southern Rwanda. PLoS Negl Trop Dis 2013;7:e2558.

9. Carpio A, Fleury A, Romo ML, et al. New diagnostic criteria for neurocysticercosis: reliability and validity. Ann Neurol 2016;80:434-442.

10. Yera H, Dupont D, Houze S, et al. Confirmation and follow-up of neurocysticercosis by real-time PCR in cerebrospinal fluid samples of patients living in France. J Clin Microbiol 2011;49:4338-4340. 


\title{
Neurology $^{\odot}$ \\ Neuroimmunology \& Neuroinflammation
}

\author{
Validity of a PCR assay in CSF for the diagnosis of neurocysticercosis \\ Arturo Carpio, Alfredo Campoverde, Matthew L. Romo, et al. \\ Neurol Neuroimmunol Neuroinflamm 2017;4; \\ DOI 10.1212/NXI.0000000000000324
}

This information is current as of January 16, 2017

\section{Updated Information \& Services}

References

Subspecialty Collections

Permissions \& Licensing

\section{Reprints}

including high resolution figures, can be found at:

http://nn.neurology.org/content/4/2/e324.full.html

This article cites 10 articles, 2 of which you can access for free at: http://nn.neurology.org/content/4/2/e324.full.html\#\#ref-list-1

This article, along with others on similar topics, appears in the following collection(s):

All Clinical Neurology

http://nn.neurology.org//cgi/collection/all_clinical_neurology

Parasitic infections

http://nn.neurology.org//cgi/collection/parasitic_infections

Information about reproducing this article in parts (figures,tables) or in its entirety can be found online at:

http://nn.neurology.org/misc/about.xhtml\#permissions

Information about ordering reprints can be found online:

http://nn.neurology.org/misc/addir.xhtml\#reprintsus

Neurol Neuroimmunol Neuroinflamm is an official journal of the American Academy of Neurology.

Published since April 2014, it is an open-access, online-only, continuous publication journal. Copyright

Copyright $\odot 2017$ The Author(s). Published by Wolters Kluwer Health, Inc. on behalf of the American

Academy of Neurology. All rights reserved. Online ISSN: 2332-7812.

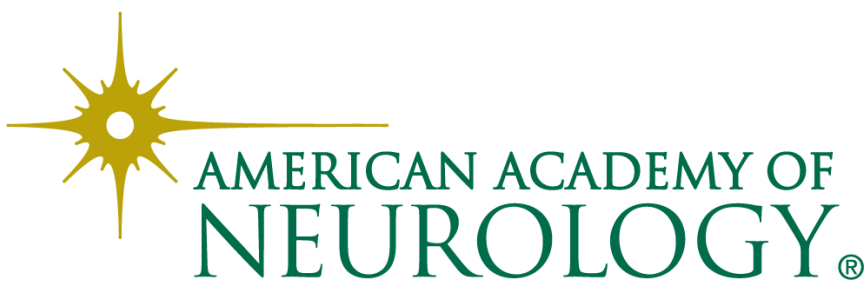

